\title{
TEATRO PARA A INFÂNCIA: UMA EXPERIÊNCIA COM A LINGUAGEM TEATRAL NA FORMAÇÃO DE PROFESSORES DA EDUCAÇÃO INFANTIL
}

\author{
Ivone Garcia Barbosa1 \\ ivonegbarbosa@hotmail.com.br \\ Natássia Duarte Garcia Leite de Oliveira² \\ natassiagarcia@yahoo.com.br
}

As funções sociais das instituições que se dedicam ao cuidado e à educação de crianças menores de sete anos têm sofrido modificações ao longo de mais de cem anos de suas trajetórias. Como mostrou Barbosa (2011), nas quatro últimas décadas uma discussão mais sistemática e crítica sobre os tipos e a qualidade de atendimento em educação infantil tem se desenvolvido. Esse movimento não aconteceu, porém, de modo espontâneo ou por pura deliberação política, já que, pelo que as pesquisas demonstram, coincide com o momento em que a estruturação econômico-social passou na modernidade a exigir cada vez mais a integração de mulheres das classes de baixa e média renda ao mundo do trabalho, aumentando, daí, a demanda por vagas em instituições educativas como creches e pré-escolas públicas e privadas (BARBOSA,1997).

Essa pauta específica conjugou-se à preocupação com a preparação de mão-de-obra qualificada para o mercado de trabalho, exigindo um olhar prospectivo quanto às funções da educação, o que mobilizou ações de movimentos sociais mais ou menos organizados. 0 conjunto desses motivos aqui citados, profundamente arraigados às transformações históricas brasileiras e internacionais, vividas e expressas nas diferentes esferas do campo social econômica, política e cultural - contribuíram na institucionalização da Educação Infantil, que passou desde a Constituição Federal de 1988 a ser considerada a primeira etapa da Educação Básica. Esse entendimento foi ratificado na Lei de Diretrizes e Bases da Educação Nacional, no

\footnotetext{
${ }^{1}$ Doutora em Educação (FE/USP); professora dos cursos de graduação e pós-graduação da Faculdade de Educação da Universidade Federal de Goiás; coordenadora do Núcleo de Estudos e Pesquisas da Infância e sua Educação em Diferentes Contextos (NEPIEC). Telefone: (62) 3209.6206/ E-mail: ivonegbarbosa@hotmail.com.br

2 Doutoranda do Programa de Pós-Graduação em Educação da Faculdade de Educação da Universidade Federal de Goiás (FE/UFG) - bolsista FAPEG; professora da Escola de Música e Artes Cênicas da UFG; coordenadora do Grupo Interdisciplinar de Estudos e Pesquisas em Interações Artísticas - SoloS de Baco. Contatos: Telefone: (62) 8128.7107/ E-mail: natassiagarcia@yahoo.com.br
} 
ano de 1996 e, posteriormente em outras versões legais e em documentos oficiais, em âmbitos nacional e local.

Esse reconhecimento sobre a importância da Educação de crianças de 0 até 6 anos passou a pautar o debate nacional sobre a qualidade no atendimento $\mathrm{e}$ todos os desdobramentos. Evidenciou-se, nesse processo que uma dimensão essencial a ser assegurada na busca pela qualidade na Educação Infantil é a formação de seus professores e de outros profissionais que atuam nesta etapa educacional. De acordo com Barbosa (2011), essa afirmativa evidencia que 0 trabalho desenvolvido em creches e pré-escolas exige dos professores amplo conhecimento político, social e cultural, além da compreensão acerca dos processos de aprendizagem e desenvolvimento humano em todas as suas dimensões. Compreende-se, dessa ótica, que é necessário modificar o panorama histórico de precariedade quanto à formação e condições de trabalho dos educadores que atuam naquelas instituições. Quanto à formação, essa compreensão favoreceu modificações importantes na legislação vigente, a qual determina que os docentes da Educação Infantil sejam formados nos cursos de Pedagogia ou Normal Superior, admitindo a habilitação mínima em nível médio, em cursos de Magistério, na Modalidade Normal. Cabe aos municípios e, supletivamente, aos estados e à União, realizar programas de formação dos professores em exercício até que todos os docentes da Educação Infantil possuam a titulação exigida. Nesse caso, têm sido propostos programas chamados de "emergenciais" pelo Ministério da Educação, como é o caso do Programa de Formação Inicial para Professores em Exercício na Educação Infantil, o Proinfantil, ofertado no período de 2005 a 2012, realizado em parceria com os entes municipais e estaduais, contando com a ação de Universidades Federais. Neste Programa propõe-se a formação de professores em efetivo exercício nos agrupamentos e nas turmas de crianças de zero até seis anos, em diferentes municípios brasileiros, os quais são formados e acompanhados por professores efetivos dos Estados e por professores efetivos dos municípios envolvidos no Programa e que assinam, juntamente com os Estados e a União um "Acordo de Participação". 


\section{A FORMAÇÃO DE PROFESSORES DA EDUCAÇÃO INFANTIL: AÇÕES E DESAFIOS NO PROINFANTIL}

Desde dezembro de 2007, foram convidadas a participar do Programa as Universidades Federais de Goiás, de Mato Grosso do Sul, do Pará e do Rio Grande do Norte, as quais de modo pioneiro buscaram implantar com apoio do MEC novo direcionamento às discussões sobre as especificidades da Educação Infantil. As quatro universidades definiram, junto ao ministério, que além da tarefa de formar os professores-formadores do Proinfantil, em nível estadual, e os professores-tutores, em nível municipal, caberia às equipes de formadores e pesquisadores das Universidades o acompanhamento e orientação pedagógica, inclusive in loco, de todas as atividades desenvolvidas e a avaliação do Programa. Deste modo, durante o Grupo II, de 2008 a 2010, as quatro Universidades se responsabilizaram pelo atendimento de 9 estados e no Grupo III, de 2010 a 2012, foram 18 estados atendidos, contando-se com a participação de 13 Universidades. Diante desse quadro, Barbosa (2011) concluiu que as ações conjuntas no campo da formação se mostram fundamentais, devendo-se ressaltar o papel da Universidade pública.

Assumir a tarefa de executar, acompanhar e avaliar projetos institucionais é uma tarefa complexa e é preciso ter-se ciência dos limites que estes têm, já que Programas emergenciais como o Proinfantil não resolverão as contradições postas no campo da formação de professores da Educação Infantil no nosso país, havendo a expectativa de que possamos construir políticas públicas que sejam capazes de modificar o cenário histórico, reafirmando-se os movimentos sociais, as crianças e suas famílias enquanto partícipes da história em movimento de construção. É importante enfatizar que nesse momento histórico, esse debate sobre a formação encontra-se imbricado nas lutas pela garantia dos direitos humanos, em especial da criança. Nessa direção, convém reafirmar as conquistas assinaladas na legislação brasileira, É preciso garantir 0 art. 227, constante no cap. VII da Constituição Federal de 1988, cuja redação foi dada pela Emenda Constitucional n 65, de 2010 e que enuncia:

É dever da família, da sociedade e do Estado assegurar à criança, ao adolescente e ao jovem, com absoluta prioridade, o direito à vida, à saúde, à alimentação, à educação, ao lazer, à profissionalização, à cultura, à dignidade, ao respeito, à liberdade e à convivência familiar e comunitária, além de colocá-los a salvo de toda forma de negligência, discriminação, exploração, violência, crueldade e opressão (BRASIL, 2010). 
Em 2008, o Núcleo de Estudos e Pesquisas e sua Educação em Diferentes Contextos NEPIEC, da Faculdade de Educação (FE) da Universidade Federal de Goiás (UFG) assumiu 0 acompanhamento e avaliação do Proinfantil nos estados de Goiás (2008-2010; 2009-2011) e do Maranhão (2008-2010). Uma das ações fundamentais do Programa se constituiu na formação continuada dos formadores da Agência Formadora - AGF (coordenadores, articuladores pedagógicos da Educação Infantil- APEI e professores formadores) e dos tutores (TR) para a compreensão do campo da Educação Infantil. Defende-se nesse sentido a importância de uma sólida formação teórico-prática dos professores de Educação Infantil, concebendo-se a formação continuada como um processo que envolve projetos em que as situações formativas acontecem em momentos específicos, conforme propostas elaboradas a partir de demandas também específicas, após a formação inicial (FREITAS, 2004; BRZEZINSKI, 2011; BARBOSA, 2011).

A formação continuada proposta pelo NEPIEC teve por objetivos: formar a Equipe Estadual de Gerenciamento (EEG), Coordenadores, Articuladores Pedagógicos e Professores Formadores das Agências Formadoras (AGF), e Tutores (TR) para atuarem no Proinfantil; possibilitar a análise e compreensão sobre a articulação entre teoria e prática no processo de constituição da práxis educativa em Educação Infantil; assegurar a qualidade do domínio acerca das especificidades do campo da Educação Infantil pelos profissionais que atuam no Programa. No período 2007-2010, o NEPIEC-UFG realizou ao todo 25 encontros de formação continuada presencial do Proinfantil com carga horária de 32 horas, sendo cinco encontros de AGF e quatro de tutores no estado do Maranhão, no Grupo II, e oito encontros de AGF e oito de tutores em Goiás, nos Grupos II e III. Na operacionalização das ações formativas, o NEPIEC contou com a participação de professores convidados, da própria FE, de outras unidades da UFG e outras IES, para tratar de temáticas específicas pertinentes aos módulos do Programa e ao domínio mais amplo da Educação Infantil.

A equipe-UFG assumiu a responsabilidade de apresentar, fundamentar e articular a discussão sobre a formação pedagógica em Educação Infantil, que abrangeu: Fundamentos da Educação (FE - fundamentos sócio filosóficos, psicologia, história da educação e da Educação Infantil) e Organização do Trabalho Pedagógico (OTP - sistema educacional brasileiro, bases pedagógicas do trabalho em educação e ação docente na Educação Infantil). A formação das AGF e TR constituiu-se em espaço aberto de interações entre os diferentes profissionais que se envolveram na formação - sendo formados em diferentes áreas de conhecimento - e aqueles 
professores atuantes no Proinfantil, em nível municipal e estadual. Vários elementos aprofundados na formação emergiram no próprio processo formativo, assumindo-se como princípio formativo a indissociabilidade entre teoria e prática. Isso significa que a equipe da UFG se permitiu elaborar e reelaborar de modo dinâmico os conhecimentos, valorizando a participação dos professores formadores e tutores nesse processo. Ademais, o NEPIEC preocupou-se em não apenas repassar os conteúdos elencados nas unidades de estudo do PROINFANTIL, tendo em vista possibilitar aos profissionais superar a mera repetição de técnicas, conteúdos e habilidades. A realização das palestras, oficinas e a produção de todo 0 material de formação buscou garantir a apropriação ampliada dos conhecimentos propostos pelo Programa, disponibilizando-se bibliografia complementar e recursos relacionados aos conteúdos dos módulos, expressando a concepção de professores como formadores e não de meros multiplicadores.

Percebe-se que a formação continuada realizada pelo NEPIEC/UFG favoreceu a articulação dos fundamentos sócio-histórico-políticos, éticos e estéticos da Educação Infantil, além de redimensionar a concepção sobre a organização do trabalho pedagógico em creches e pré-escolas. Desde a formação no primeiro módulo, nossa equipe UFG se voltou para a sensibilização dos profissionais da AGF e dos tutores para a necessidade de assunção da Educação Infantil como etapa específica e essencial na formação da criança, possibilitando uma reflexão de natureza crítica sobre as concepções e práticas docentes, a fim de incorporar novos paradigmas teórico-metodológicos para pensar a infância e a docência.

\section{UMA EXPERIÊNCIA NO PROINFANTIL: NOTAÇÕES PRELIMINARES ACERCA DO TEATRO NA EDUCAÇÃO INFANTIL}

Entre as várias oficinas de formação que foram realizadas no Proinfantil pela equipe do NEPIEC, destacamos as referentes às Artes Visuais e Cênicas, sendo esta última o foco de nossa análise. Atualmente, é consenso entre os pesquisadores e educadores brasileiros que a Educação Infantil, em seu processo histórico de lutas, materializa-se no âmbito das políticas públicas com a finalidade de promover o desenvolvimento integral da criança em todos os seus 
aspectos: físico, motor, cognitivo, social e efetivo, devendo compreender de modo articulado e integrado o cuidar e o educar num espaço educacional que deve proporcionar à criança:

experiências concretas, expressões e relações multifacetadas: as múltiplas linguagens, a corporeidade e o movimento, atividades artísticas (artes visuais, música, artes cênicas, literatura) e que envolvam várias áreas de conhecimento (matemática, ciências naturais e sociais), a imaginação e criação (BARBOSA, 2010, p. 3 - grifos nossos, parênteses do autor).

Embora 0 teatro, com inserções ainda embrionárias, venha sendo utilizado como meio de aprendizagem na educação de crianças pequenas, nem sempre aparece em destaque. Em geral, verificam-se experiências restritas dos professores com arte, sujeitas, inclusive às contradições presentes nos currículos e nas propostas e práticas pedagógicas, sem conhecimento sobre os processos de desenvolvimento estético na infância. Por este motivo, devido ao tempo reduzido da Oficina Múltiplas Linguagens: música, teatro e gestualidade³, no Programa Proinfantil, durante as oficinas de formação propostas em Goiás e no Maranhão, optamos por trabalhar especificamente com a exploração de atividades para os professorescursistas. Neste caso, foi pensada uma dinâmica a qual contemplasse uma sensibilização dos professores acerca da importância Teatro na Educação Infantil, mantendo sempre a preocupação de fazer referências sobre ao trabalho cotidiano com as crianças. Assumimos no processo a concepção de Soares, segundo o qual:

\begin{abstract}
na relação estética com o mundo, geralmente, o indivíduo elabora e expressa percepções, emoções, valores, sentimento, sentidos e significados que qualificam seu modo de vida. Por meio de sua relação, intervenção ou mediação ativa no mundo, de sua projeção criativa e estética no mundo, é possível ao indivíduo estabelecer conteúdos do humano por uma forma concreto-sensível determinada, a qual possui sua melhor expressão, elaboração e intencionalidade nas criações artísticas, particularmente, nas linguagens da música, artes plásticas, dança, teatro, literatura, fotografia, cinema, entre outras (SOARES, 2006, p. 72).
\end{abstract}

Com essa perspectiva, foram trabalhados conceitos importantes para reflexão da educação corporal, os quais se relacionam diretamente com o teatro, como: natureza, corp(oralidade) - abrangendo corpo-mente, formação social do corpo, imagem do corpo, corpo nas artes, corpo como instrumento, a razão em detrimento da emoção -, subjetividade e

\footnotetext{
${ }^{3}$ A Oficina Múltiplas Linguagens: música, teatro e gestualidade aconteceu durante o Encontro de Formação de Professores, Formadores e Tutores do Proinfantil nos Estados de Goiás e Maranhão, e ocorreu respectivamente nos períodos de 08 a 17 de junho e de 29 a 03 de julho do ano de 2009. Foi elaborada pela Profa. Ms. Natássia Duarte Garcia Leite de Oliveira (Teatro) e pelo Prof. Especialista Gleyson Batista Rios (Educação Física), sob orientação e coordenação da Profa. Dra. Ivone Garcia Barbosa (Educação) e do Prof. Dr. Marcos Antônio Soares.
} 
objetividade. No primeiro momento da oficina, foram realizadas dinâmicas com música, dança e outras formas de gestualidade buscando reconhecer as possibilidades de interação do movimento com as múltiplas linguagens. Para explorar as dimensões do corpo e a espacialidade trabalhamos com exercícios de relaxamento e tensão - movimentos aberto, grande, pequeno, fechado, frontal, lateral, acima, abaixo, em plano baixo, em plano médio, em plano alto, em diagonal - e reconhecimento do espaço e do corpo do outro com os olhos fechados. 0 objetivo foi de conduzir as professoras-cursistas à percepção do 'movimentar-se' humano, nas formas como se apresentam no teatro e na dança, e sua importância na sensibilização e na formação do sujeito.

Pudemos observar que quando se propõe esse tipo de vivência, os professores/cursistas sentem necessidade de se envolverem no processo para refletirem e pensarem criticamente acerca de suas experiências com o ensino, inclusive, preconceitos que vivenciam e reproduzem diariamente. Durante o trabalho corporal, por exemplo, percebíamos a dificuldade e resistência em realizar certos movimentos, além do constrangimento em se movimentar junto e/ou próximo aos outros cursistas. O contato com o próprio corpo e o contato com o corpo de outro provocava esse incômodo. Por meio dessas limitações corporais encontradas nos exercícios e a partir das relações provocadas nas atividades é que se iniciaram as discussões sobre o corpo e a cultura, as artes e a educação física. Assim, analisamos coletivamente o corpo como produtor de relações, conquistas e aprendizagens, compreendendo a importância das sensações e do movimento no processo de aprendizagem e desenvolvimento das crianças, refletindo sobre os conhecimentos que envolvem e marcam os corpos dos docentes e as suas relações pedagógicas.

Em outro momento da oficina, sugerimos a composição coletiva de situações dramáticas a partir das Fábulas de La Fontaine, com suas respectivas apresentações. Se por um lado 0 trabalho com as fábulas redundaria uma reprodução da forma de 'ensinar o teatro' nas instituições, por outro, a escolha refletiria a possibilidade de tecermos críticas acerca das práticas cotidianas das professoras. 
No trabalho com o Teatro na Educação Infantil temos uma gama de proposições metodológicas às vistas do brincar $^{4}$, do faz-de-conta ${ }^{5}$, do jogo e da contação de histórias, aspectos destacados por Vigotski $(2001,2009)$. No caso da contação de histórias, ela é bastante frequente na Educação Infantil e não é diferente nos Estados de Goiás e do Maranhão. Aquela, muitas vezes, ocorre com a utilização dos livros de literatura infantil, os quais contemplam diversos gêneros literários, dentre eles a fábula, muito escolhida por professores, principalmente pela conhecida "moral da história". Mas também porque

Contar histórias é [...] uma atividade muito vivenciada na infância. Tal atividade deve ser encarada como uma atividade lúdica e um recurso importante para promover 0 desenvolvimento das crianças, pois nessa ação estão envolvidos o pensamento, a imaginação, a fantasia e a criatividade. Esta atividade é considerada também como uma fonte de prazer e de estimulo à expressão da criatividade. Ao contar, recontar e criar sua própria história, a criança, mesmo ainda não alfabetizada, constrói sentidos e significados, expressa sentimentos, cria seu próprio mundo vivenciando suas fantasias, oportunizando o conhecimento de si e do ambiente que a cerca (MOZZER apud MOZZER e BORGES, 2008, p.313).

No momento de avaliação e de análise das cenas durante o curso no Proinfantil trouxemos os conceitos referentes ao jogo protagonizado (como atividade principal da criança) e ao jogo dramático (como teatralidade assumida).

\begin{abstract}
a teatralidade emerge da interação das crianças com o jogo dramático, da manipulação coletiva dos sinais da realidade, mediada pela necessidade de produção de sentido, própria à comunicação teatral: "é utilizando o artifício, afirmando plenamente a teatralidade, que o jogo dramático se transforma num instrumento de análise do mundo (RYNGAERT apud SANTOS, 2002, p.50).
\end{abstract}

O jogo teatral trabalha na linha tênue dos limites, das regras e da liberdade de criação. Neste sentido, embora o brincar, o jogo, o faz-de-conta integrem a linguagem teatral, o Teatro é um campo de conhecimento amplo, que possui fundamentos e especificidades distintas da brincadeira, do jogo e do faz-de-conta. Faz-se necessária essa colocação, uma vez que encontramos, muitas vezes, uma equivalência entre 'brincar de faz-de-conta' e o jogo teatral, na medida em que há um suposto "distanciamento da vida comum, da realidade cotidiana".

\footnotetext{
${ }^{4} \mathrm{O}$ brincar segundo a teoria sócio-histórica dialética é importante para a Educação Infantil, porém, não porque a brincadeira é uma atividade natural e principal da infância, mas por ser objetiva, real, concreta, pois a brincadeira é uma atividade na qual a criança se apropria do mundo historicamente construído, da maneira que é possível num determinado momento.

5 "Através das interações que estabelecem com diversos parceiros, particularmente graças aos jogos de faz de conta, nos quais a criança aprende a assumir diferentes personagens, ou seja, aprende a se pôr em uma perspectiva diferente da sua e a reagir às suas próprias ações como os outros fariam, ela apreende os papéis que existem, por exemplo, na família, e em outros contextos" (OLIVEIRA, 2011, p.39).
} 
Entretanto, contrariamente, sabemos que há práticas teatrais - algumas ligadas às noções do psicodrama, a exemplo - as quais se aproximam da realidade cotidiana da criança. Em decorrência, esta realidade pode ser elucidada por uma historia de faz-de-conta, mas além, pode culminar num jogo dramático. Ou seja, nem sempre o faz-de-conta transfigura-se em ato teatral e, nem sempre, o Teatro como linguagem é faz-de-conta.

Neste contexto, o Teatro para a Infância, como identificamos nas nossas formações de professores, relacionava-se primordialmente com aspectos belos, positivos e alegres, os quais possibilitam sonhos, imaginação, fantasias, fuga do real. Por isso, no processo de formação ficou marcante para os profissionais da educação (professores-cursistas) como as experiências estéticas e as artes estão também relacionadas às vivências da realidade. Isso significa que passaram a reconhecer o teatro não só como campo dos sonhos, da imaginação, da fantasia. Kühner diz:

\begin{abstract}
Você não pode chegar e dizer - isto é uma cadeira - se a cadeira não estiver ali, porque segundo alguns, a criança tem que ver a cadeira. Isso não se confirma [...] porque a criança tem a imaginação aberta. Se eu lhe mostrar uma caneta e disser isto aqui é uma cadeira - e se eu tiver a possibilidade de convencê-la, se eu for realmente convincente e tiver técnica teatral para transformar uma caneta em uma cadeira, a criança não vai nem por um momento questionar isso (KÜHNER, 2003, p.67).
\end{abstract}

Com essa referência fica clara a capacidade de imaginação da criança, entretanto, não parece verdade que a criança utiliza a imaginação em seu processo de aprendizagem e desenvolvimento sem restrições do que é real ou não. 0 Teatro não é só a possibilidade de um mundo de fantasia para a criança, ele é também uma realidade e pode vir a ser transformador da realidade cotidiana. $O$ jogo dramático, que não é estritamente o jogo lúdico, é um momento no qual a criança estabelece contato não só com ideias abstratas e virtuais, digamos, mas, sobretudo, com a exploração do imaginário e da transformação das ideias em materialidade artística.

Se é verdade que a criança tem uma imaginação fantástica e embarca facilmente nas histórias contadas, é também verdade que ela lida com a materialidade. A criança escreve sua história com o corpo e no corpo identificamos, portanto, não só o envolvimento da subjetividade, mas também das condições objetivas que a formam. Em tal contexto, a relação e a tensão entre realidade e fantasia existem, tal como a subjetividade e a objetividade. Desta forma, 
desmistificando a arte somente como um produto do devaneio, na oficina de formação foi possível compreender o teatro como trabalho que também se articula com a realidade. Pois entendemos que

[...] a arte decorre de um processo do trabalho de um sujeito em um dado processo de criação, conhecimento e expressão. Pela sua capacidade de perceber, conhecer, projetar e transformar o mundo, o artista apropria-se de uma dada realidade concreta e reapresenta-nos - mediado por determinado meio expressivo e por sua concepção - como realidade artística (SOARES, 2006: p. 75).

E, portanto, as tensões e o mal estar que fazem emergir o grotesco, a morte, o fracasso, os sentimentos, as emoções também estão presentes na realidade e na arte, assim como estão presentes na infância e, não menos, podem estar presentes no teatro para a infância.

Neste sentido, a Educação Infantil deve ser percebida na totalidade, na relação com os aspectos físicos, cognitivos, intelectuais, estéticos e técnicos. A criança deve ser entendida como um ser inserido nas relações sociais, que é constituída e constituinte da história e que esta exerce um papel ativo na construção de conhecimento e formação de conceitos. A Educação Infantil nessa perspectiva tem um papel fundamental possibilitando a socialização de conhecimentos historicamente produzidos, ensinando às crianças "[...] a compartilhar ativamente (não sem contradições e tensões) dos diversos valores da existência e do mundo trocarem conhecimento, vivenciarem papéis e estabelecerem práticas criativas e contemporâneas [...]" (BARBOSA, 1997, p. 149).

O brincar na Educação Infantil, por exemplo, é importante, mas não deve ser o eixo norteador, pois é necessário que se compreenda que a prática pedagógica do professor deve envolver um processo mais amplo "[...] do que simplesmente um desenrolar de atividades recreativas ou de entretenimento" (BARBOSA, 1997, p. 132). É necessário que a atividade pedagógica na Educação Infantil seja compreendida além de memorização e repetição, e em especial que a Educação Infantil está além de atividades recreativas, entretenimento, ou simplesmente fazer tarefas (BABROSA, 2010).

Os professores-cursistas nas oficinas se mostraram atentos aos objetivos das atividades propostas, tentando perceber qual a melhor forma de desenvolver as dinâmicas com outros professores, em formações das quais são responsáveis. 0 critério de seleção das atividades, 0 
tempo e a ordem de realização destas na oficina e suas relações com os conceitos discutidos contemplaram uma necessidade dos cursistas de conhecer procedimentos para organização de atividades no ensino das artes.

Uma das perguntas levantadas ao final da oficina foi: será que 'o conhecimento das metodologias' garante que o ensino do teatro aconteça? Pareceu-nos uma promessa um tanto arriscada afirmar que sim, assim como se torna demasiadamente arriscado pensar somente em "aplicar" tais metodologias no contexto da Educação Infantil, visto que esta atitude afirma um determinismo por parte do professor, uma vez que "saber metodologias" não é necessariamente garante uma ampla experiência artística e a elaboração de uma prática crítica. Comumente, foram identificadas nas falas dos cursistas expressões como "aplicação", "teatro como instrumento", "teatro como ferramenta pedagógica", entre outras. A questão latente é "elas refletem uma reprodução irrefletida do tecnicismo, do pragmatismo e do instrumentalismo pungentes no cerne da educação em arte no Brasil?". A questão conseguinte se instaura do incômodo: porque não conseguimos superar a noção do teatro como instrumento?

O teatro para a infância não se constitui apenas como meio didático para favorecer a desinibição dos "tímidos" e abrandamento dos "hiperativos", como já ouvimos em alguns discursos de professores sobre a necessidade e função do teatro na escola. Além disso, é preciso superar concepções conservadoras que veem no teatro para a infância um meio disciplinador ou como fórmula que dê conta de uma individualidade a que opõem e antagonizam a ação coletiva. De acordo com nossas experiências formativas e com nossas pesquisas, é possível ousar e criar novas perspectivas sobre o papel do Teatro na Educação Infantil. Sim, o teatro pode ser também parte da construção da realidade do sujeito e suas singularidades. Não, o teatro não deve servir apenas como instrumento de treinamento, desinibição, abrandamento, doutrinamento de corpos e comportamentos. As múltiplas linguagens que constituem o teatro fazem dele uma linguagem polifônica e que tem papel mediador privilegiado na relação dialética entre a criança e o mundo. Portanto, admite-se aí um campo de conhecimento, não meramente instrumental, o qual se apresenta como uma forma de realizar trabalho.

\section{CONSIDERAÇÕES FINAIS}


É necessário que haja um reconhecimento e uma formação de professores que leve em consideração as e especificidades da Educação Infantil, os estudos da área acerca da infância, as instituições de atendimento à criança, concepções e práticas pedagógicas que a norteiam.

Com a experiência da Oficina Múltiplas Linguagens: música, teatro e gestualidade, a qual teve como foco 0 trabalho com o teatro, pudemos constatar que neste momento os desafios se tornam mais aparentes que as superações. Emergiram no período da oficina as tensões e contradições entre teoria e prática no teatro e a práxis na sala de aula. Também, apareceram as contradições e condições que envolvem os currículos e as práticas das instituições que buscam contemplá-los. Alguns profissionais reclamaram sobre as dificuldades de realização de atividades no campo das artes em suas respectivas instituições por falta de espaços adequados. Outros falaram da resistência das crianças, dos pais e dos próprios educadores às propostas de atividades que modificam a rotina das instituições de ensino ou que exigem novas concepções e sentimentos estéticos. Então, se por um lado as instituições e os professores percebem a importância do ensino do teatro, no discurso e na prática, ainda verificam-se escassez nos materiais pedagógicos, limitações no espaço físico, ausência de formação específica e obrigação do teatro servir unicamente a datas comemorativas das instituições.

$\mathrm{Na}$ oficina, ficou evidente que ainda não conseguimos superar, em grande medida, as discriminações com a profissão, o descaso pela categoria e os preconceitos que ainda sofrem os professores de arte. Numa época em que não superamos a era do entretenimento, ainda se alude à ideia de que na Educação Infantil o professor realiza com sua turma de crianças os "teatrinhos" - ou "o teatro como instrumento para apresentação de datas comemorativas", como aparece na fala de alguns dos professores -, também não superamos dissociação entre teoria e prática no ensino do teatro; de forma e conteúdo; de homem e natureza; de educação e cultura. Mais grave que essa dicotomização, está a luta do professor, por meio do "improviso", com a prática da polivalência encoberta pelo discurso da interdisciplinaridade. Discurso o qual nos faz pensar até que ponto a superação dos desafios do Teatro na Educação Infantil não se transformam numa conciliação dos problemas que enfrentamos, na medida em que ainda se sobressai a epígrafe: "Ah! O professor sempre se vira mesmo... ele é criativo!". 
Em muitas falas dos professores ficou explícita a premissa de que 0 teatro é imprescindível para a formação integral do sujeito. Sob esta perspectiva está presente a esperança pelo desfrute de um direito de acesso à diversas linguagens e expressões humanas, a paixão pelo teatro, mas também está presente a idealização da arte e do ensino da arte. O que parece um movimento de inserção gradual nas instituições e de paciência histórica por parte dos profissionais, em geral, é mais uma situação absurda que a precariedade das instituições impõe ao trabalho dos professores. Espera-se que ele seja "o salvador" criativo e mostre trabalho mesmo na precariedade, quando na verdade, precisava-se assumir a idealização contida neste espectro. $O$ fato é que se torna inevitável o fracasso do professor que na Educação infantil se propõe a utilizar e vivenciar o teatro em tais condições. Para além dessa dificuldade no campo do exercício docente, encontramos ainda as reais limitações de classe e culturais: os professores sequer têm, na sua maioria, acesso ao teatro, desconhecem sua materialização no cotidiano ou mesmo em momentos de lazer, tidos por eles como momentos "excepcionais" em que podem ter acesso à arte.

Deparamo-nos então com o problema: até que ponto 0 ensino do teatro garante efetivamente uma formação do sujeito neste contexto idealizado de educação e da cultura? E, em que medida se pode cobrar uma experiência efetiva de teatro nas condições reais das Instituições de Educação Infantil?

Precisamos pensar que a formação em/com/pelo teatro está atrelada a uma estética cultural e educacional; e às formações específicas das singularidades de cada ser humano. $E$ isso interfere e contamina a práxis. É relevante que esteja em pauta a possibilidade da educação pelo teatro e o teatro como forma de educação. Contudo, não podemos ser menos exigentes com relação às proposições de professores que utilizam a linguagem teatral na formação de crianças pequenas, fazendo-se necessário o conhecimento dos campos para compreensão de suas especificidades, bem como suas interseções. Mesmo que, inicialmente, tenhamos que assumir os limites, as dificuldades, os desafios, apontando as possíveis superações do campo do Teatro na Educação Infantil.

Com isso, finalmente podemos afirmar que uma coisa é o que pode ser o teatro na Educação Infantil, outra coisa é o que esperamos e desejamos. Concluindo, o próprio teatro tem a sua máscara. É necessário, pois, saber lidar com as realidades, idealizações e projeções. É 
preciso pensar nos métodos que contaminam a estrutura social e, não menos o teatro. Entendemos o desejo de mudança e a perspectiva de transformação da Educação Infantil com a presença do Teatro, contudo, em que medida esse discurso apresentado não apresenta reprodução? O teatro ou as artes não garantem a subversão de estruturas rígidas e tabus presentes nas instituições de ensino, mas a forma como ele pode vir a operar possibilita alguma potencialidade para a transformação. Então: ousemos.

\section{REFERÊNCIAS}

BARBOSA, Ivone G. Pré-escola e formação de conceitos: uma versão sócio-históricodialética. 1997. São Paulo: FEUSP, 1997, 169f. (Tese de Doutorado).

A prática pedagógica na educação infantil. In: OLIVEIRA, D. A; DUARTE, A. M. C.; VIEIRA, L. M .F. (orgs.). Dicionário de trabalho, profissão e condição docente. Belo Horizonte: Faculdade deEducação/UFMG, 2010.

O Proinfantil e a formação do professor. P.385-398. In: Educação Infantil - Dossiê. Retratos da Escolal Escola de Formação da Confederação Nacional dos Trabalhadores em Educação (Esforce) - v. 5, n. 9, jul./dez. 2011 - Brasília: CNTE, 2007-

BRASIL. Constituição da República Federativa do Brasil. Lei Federal de 5/10/1998. Brasília: Senado Federal, 2009.

BRASIL. Lei n 9.394/96, de 20 de dezembro de 1996. Estabelece as Diretrizes e Bases da Educação Nacional. Diário Oficial da União, Brasília, DF, 23 dez. de 1996.

BRASIL. Emenda Constitucional n 65, de 2010.

BRZEZINSKI, Iria et all. ANFOPE em movimento: 2008-2010. Brasília: Liber Livro/ ANFOPE/CAPES, 2011.

FREITAS, Helena Costa Lopes de. Novas políticas de formação: da concepção negada à concepção consentida. In: BARBOSA, Raquel Lazzari Leite. (org). Trajetórias e perspectivas da formação de educadores. São Paulo: UNESP, 2004.

KHÜHNER, Maria Helena (org.). 0 teatro dito infantil. Blumenau: Cultura em Movimento, 2003.

MOZZER, Geisa. N. S.; BORGES, Fabrícia B. A criatividade infantil na perspectiva de Lev Vigotski. Revista da Faculdade de Educação da UFG. n 33. Goiânia: UFG, 2008.

OLIVEIRA, Zilma de Moraes Ramos de. Jogos de papeis: um olhar par as brincadeiras infantis. São Paulo: Cortez, 2011.

SANTOS, Vera Lúcia Bertoni dos. O Teatro como sistema de conhecimento. In: Brincadeira e conhecimento: do faz-de-conta à representação teatral. Porto Alegre: Mediação, 2002. 
SOARES, Marcos Antônio. Entre sombras e flores: continuidades e rupturas na educação estética de devotos-artistas de Santos Reis. Goiânia. Tese de Doutorado defendida pelo Programa de Pós-Graduação em Educação da Universidade Federal de Goiás, 2006.

VIGOTSKI, Lev S. Psicologia Pedagógica. São Paulo: Martins Fontes, 2001. Imaginação e criação na infância. São Paulo: Ática, 2009. 